\title{
Factores psico-socio-ambientales asociados al estrés laboral en profesores chilenos del ámbito rural y urbano
}

\section{Psycho-Social-Environmental Factors Associated with Work- Related Stress in Chilean Teachers in Rural and Urban Areas}

\author{
Juan Rubio González* \\ Universidad de Atacama, Copiapó, Chile \\ ORCID: https://orcid.org/0000-0001-8118-5104 \\ Paula Andrade Daigre \\ Universidad de Artes, Ciencias y Comunicación, Santiago, Chile \\ ORCID: https://orcid.org/0000-0002-6687-0768 \\ Gabriela Fravega Araneda \\ Escuela Viopir de Nancul, Panguipulli, Chile \\ ORCID: https://orcid.org/0000-0001-6860-6621 \\ Soledad Macalusso Salgado \\ Escuela Particular a Foresta, Malleco, Chile \\ ORCID: https://orcid.org/0000-0002-8582-373X \\ Andrés Soto Sandoval \\ Vicaría para la Educación, Arzobispado de Santiago, Santiago, Chile \\ ORCID: https://orcid.org/0000-0003-2847-637X
}

Recibido 28-06-19 Revisado 10-07-19 Aprobado 06-09-19 En línea 20-09-19

*Correspondencia

Email: juan.rubio@uda.cl
Citar como:

Rubio González, J., Andrade Daigre, P., Fravega Araneda, G., Macalusso Salgado, S., \& Soto Sandoval, A. (2019). Factores psico-socio-ambientales asociados al estrés laboral en profesores chilenos del ámbito rural y urbano. Propósitos y Representaciones, 7(3), 300-322. doi: http://dx.doi.org/10.20511/pyr2019.v7n3.358 


\section{Resumen}

El objetivo de este estudio fue indagar acerca de las percepciones que tienen los profesores de colegios urbanos y rurales sobre los factores psico-socio-ambientales desencadenantes del estrés laboral docente. Considerando un enfoque cualitativo fenomenológico, con alcance exploratorio, se utiliza un diseño de estudio de casos con docentes de la localidad de Collipulli, sur de Chile, con técnica de Grupo de Discusión para recabar datos, y análisis de contenido de los mismos, del que se desprende que los profesores tienden a percibir que factores ambientales tales como liderazgos deficientes, roles docentes desconfigurados, agobio laboral, sumado a aulas sobrepobladas, alumnos desmotivados, y desvinculación de los padres de su rol educativo, serían las principales amenazas para su salud mental. Se discute sobre los recursos psicológicos, estilos de afrontamiento y percepción del contexto que presentan los profesores del estudio.

Palabras Clave: Estrés laboral docente; Percepción; Factores psicológicos; Factores sociales; Factores ambientales.

\section{Summary}

The aim of this study was to investigate the perceptions that teachers in urban and rural schools have of the psycho-social-environmental factors that trigger teacher work stress. Considering a phenomenological qualitative approach, with exploratory scope, a case study design is used with teachers from the locality of Collipulli, southern Chile, with a Discussion Group technique to collect data and content analysis, from which it can be inferred that teachers tend to perceive that environmental factors such as deficient leaderships, undetermined teaching roles, work overload, overcrowded classrooms, unmotivated students, and disconnection of parents from their educational role, would be the main threats to their mental health. The psychological resources, coping styles and context perception presented by the teachers in the study are discussed.

Keywords: Teachers Occupational Stress; Perception; Psychological Factors; Social Factors; Environmental Factors.

\section{Introducción}

La salud mental de los docentes es una problemática de interés desde variados ámbitos; autoridades, gremios e investigadores de diversos campos del saber, han comprendido que el educador ejerce una profesión mentalmente demandante, antecedente reconocido por la Organización Mundial de la Salud (OMS), desde donde se establece que enseñar es una de las ocho ocupaciones más estresantes, al mismo nivel que ser médico, paramédico o enfermera (Bryce, 2001).

En Chile, una serie de estudios, en su mayoría de carácter cuantitativo, han indagado sobre el impacto de las condiciones de trabajo en la salud de los profesores (Parra, 2005; Cornejo, 2008, 2009), la calidad de vida del docente y su influjo en el rendimiento de los alumnos (Villarroel \& Wooding, 2005), factores asociados a la generación de estrés en la actividad cotidiana (Corvalán, 2005), y aspectos emocionales del fenómeno en el llamado síndrome de Burnout (Asún, Molina \& Real, 2002; Darrigrande \& Durán, 2012; Jiménez, Jara \& Miranda, 2012).

En términos cualitativos, los estudios constatan la existencia de un "malestar docente" vinculado a una serie de transformaciones sociales ocurridas durante las últimas décadas, que han impactado fuertemente en el ámbito de las escuelas urbanas y rurales (Cornejo, 2008; Williamson, 2004). En ese sentido, investigaciones desde este enfoque muestran que las creencias del profesor representan un sistema direccionador que permiten explicar una serie de fenómenos que ocurren en el ámbito educativo (Vera, Osses \& Schiefelbein, 2012), como el énfasis en el factor medioambiental que se esgrime en la educación rural (Díaz \& Osses, 2013). 
La OMS entiende el estrés laboral como la "reacción que puede tener un individuo ante las exigencias y presiones laborales que no se ajustan a sus conocimientos y capacidades, y que ponen a prueba su capacidad para afrontar la situación" (OMS, 2004, p.3). En esa línea, respecto al fenómeno del estrés, de acuerdo al estudio realizado por la UNESCO en 2005, se trataría de la tercera sintomatología más presente entre los educadores (41,8\%), después de la disfonía/afonía $(46,2 \%)$ y del colon irritable (44,3\%) (Robalino \& Körner, 2005).

Al respecto, los modelos explicativos del fenómeno, que cuentan con mayor sustento empírico y teórico en el ámbito docente son el de "desajuste esfuerzo-recompensa" de Siegrest y el modelo de "control-demanda-apoyo social" de Karasek (Cornejo, 2009). Dichos modelos enfatizan la importancia de aspectos tales como "nivel de demanda laboral percibida", "grados de recompensa", "control y autonomía", "valoración social", "apoyo social" y "significatividad" del trabajo (Karasek \& Theorell, 1990).

Respecto a los factores sociales asociados al fenómeno, la OMS recomienda analizar las condiciones estructurales e intergrupales que son potenciales generadores de estrés en los profesores (Napione, 2008; OMS, 2004). Ello implica, factores como el bajo reconocimiento social, la falta de redes de apoyo, los cambios ocurridos en el contexto educacional, eventuales paralizaciones de actividades por protestas gremiales y la percepción de inseguridad que pueden sentir los docentes por conflictos en la comunidad local, derivados de problemas como marginalidad, violencia, consumo de drogas o pobreza (Robalino \& Körner, 2005).

De hecho, el estudio de la UNESCO de 2005 reporta que la labor docente en establecimientos educacionales subvencionados y municipalizados en Chile es de alta vulnerabilidad, producto de que los profesores adolecen de tiempo para descansar, infraestructura adecuada y medidas de seguridad apropiadas, entre otras características organizacionales (Parra, 2005). Junto con estos "estresores sociales crónicos" (Sandín, 2003), parece necesario considerar una serie de situaciones vinculadas con el rol desempeñado, aunque también con el contexto social en el cual éste se ejerce.

En esa lógica, el estrés laboral de los profesores se haya influido también por factores ambientales, referidos a las situaciones que se dan al interior de la organización y que afectan directa o indirectamente el desempeño docente (Asún, Molina \& Real, 2002). Al respecto, se señalan la sobrecarga de trabajo, dificultades conductuales de los alumnos, baja motivación de éstos, clima laboral, exceso de alumnos en la sala, baja remuneración económica, malas condiciones de trabajo, presiones temporales y cambios en las demandas de currículum (Corvalán, 2005).

Asimismo, la literatura reporta una serie de factores psicológicos, como la autopercepción de eficacia, el nivel de autonomía, las estrategias de afrontamiento, las expectativas personales, las relaciones interpersonales y la significatividad social de la labor docente, cuya merma se identifica como una de las 20 causas del estrés laboral entre educadores (Napione, 2008).

Por otra parte, se deben considerar factores vinculados al contexto geográfico en el cual el profesor ejerce su profesión. Por ejemplo, el ámbito rural presenta cualidades geográficas, climáticas y espaciales, junto con códigos culturales bien particulares. Estudios muestran que el papel del profesor rural no está delimitado al espacio físico del colegio, ni al espacio mental de la relación profesor-alumno, sino que se amplía al de un profesional que se concibe al servicio de la comunidad, bregando por conciliar el currículo escolar con el conjunto de creencias y comprensiones culturales de su medio (Vera, Osses \& Schiefelbein, 2012).

En ese sentido, la región de la Araucanía, en el sur de Chile, no sólo posee un carácter urbano y rural, sino que aparece como un territorio con límites culturales difusos, donde campo y ciudad se imbrican, nutren y confunden dinámicamente (Williamson, 2004), y donde escuelas y 
profesores deben responder a las exigencias de los programas educativos en un contexto social de cambios ambientales y socioculturales vertiginosos (Díaz \& Osses, 2013). Particularmente en la localidad de Collipulli, los estudios revelan un incremento de las licencias médicas entre los profesores, con la consiguiente repercusión pedagógica que ello implica (Municipalidad de Collipulli, 2012), de ahí que surge como un contexto con características particularmente idóneas para tratar de responder a la pregunta que impulsa esta investigación: ¿cuáles son las percepciones que tienen los profesores de colegios urbanos y rurales en relación a los factores desencadenantes del estrés laboral docente?

En ese contexto, y considerando que las percepciones influyen en el propio desempeño, y ya que el profesor es uno de los principales protagonistas del proceso educativo, el presente trabajo se propuso indagar acerca de las percepciones que tienen los profesores de colegios urbanos y rurales de la localidad de Collipulli, sobre los factores psico-socio-ambientales asociados al estrés laboral. Para este estudio, se conceptualiza la percepción como el proceso mediante el cual la experiencia sensorial se interpreta y significa según determinadas influencias culturales, sociales e históricas que orientan la manera como los grupos sociales se apropian del entorno (Vargas, 1994).

Desde esa perspectiva, con esta investigación se pretende realizar un aporte al campo de la psicología y la educación, al contribuir al conocimiento de un problema que atañe a la sociedad en su conjunto, ya que la calidad de la enseñanza se relaciona, entre otros aspectos, con las características personales y profesionales del profesor y con el modo en que enfrenta y conduce el proceso pedagógico (Vera, Osses \& Schiefelbein, 2012).

\section{Método}

La metodología del estudio se fundamentó en el enfoque cualitativo fenomenológico, siguiendo la lógica husseriana de indagar el discurso, experiencias, actitudes, creencias, pensamientos, reflexiones e interacciones simbólicas y significativas de los profesores. El alcance exploratorio del estudio hizo posible una familiarización con un fenómeno que, si bien ha sido estudiado, era necesario realizar un acercamiento inductivo que enfatice el modo en que el profesor interpreta los principales factores que inciden en el estrés laboral docente, pero abordándolos en sus contextos de manera holística y lo más natural posible (Taylor \& Bogdan, 1987). En ese sentido, el estudio presenta un diseño que asume la lógica del estudio de caso (Stake, 1999) intentando comprender las significaciones subjetivas realizadas por los participantes, respecto al fenómeno estudiado.

Como técnica de recolección de datos, se utilizó el Grupo de Discusión, que consiste en reunir a un grupo de participantes y suscitar una conversación cuidadosamente planeada sobre un tema, para obtener procesos reflexivos colectivos (Krueger, 1988). Los participantes del estudio se seleccionaron a través de un muestreo no probabilístico intencionado, con el criterio de casostipo, ya que era necesario garantizar la mejor calidad y riqueza informativa posible. Para ello, los docentes seleccionados fueron invitados a participar voluntariamente mediante una carta explicativa de los objetivos y solicitándoles, además, la lectura y firma de un consentimiento informado.

Se conformaron dos Grupos de Discusión en la localidad de Collipulli, los que se reunieron 1 vez con una duración promedio de 90 minutos, lográndose la saturación de información esperada. El primer grupo estuvo conformado por 7 profesores del contexto rural, 4 hombres y 3 mujeres, de entre 3 y 30 años de experiencia en Educación General Básica y actualmente ejerciendo en escuelas municipales. El segundo grupo fue integrado por 7 profesores de Educación General Básica del contexto urbano; 3 hombres y 4 mujeres, de entre 3 y 30 años de experiencia profesional y en actual ejercicio docente en la localidad.

\section{Interpretación y análisis de datos}


Realizada la transcripción literal de la información obtenida, los datos se interpretaron y analizaron utilizando la estrategia del Análisis de Contenido, el cual permitió formular inferencias sobre los razonamientos y visiones de los profesores (Krippendorff, 1990). El análisis del contenido del discurso docente, fue apoyado por el paquete informático Atlas.ti, obteniéndose dos Unidades Hermenéuticas (HU), desde donde se identificaron 186 citas textuales, que se redujeron, organizándolas en códigos, los que se transformaron en categorías, de acuerdo con las dimensiones previamente establecidas.

Para asegurar la rigurosidad en la fase de interpretación de datos (codificación y categorización) y el posterior análisis, en una primera instancia, ello fue realizado separadamente por los investigadores, para luego contrastar los códigos y determinar la representatividad con el contenido analizado y los objetivos propuestos, cumpliendo así con los criterios de intersubjetividad (Krause, 1995) y de triangulación por investigadores (Denzin, 1989).

\section{Resultados}

De acuerdo con lo expresado por los profesores, se establecieron cuatro categorías generales, en base a las cuales se detallan los resultados más destacados por cada una, que a continuación se analizan:

\section{El concepto de estrés laboral docente}

En general, los profesores entrevistados, carecen de un concepto estructurado sobre el estrés laboral. Incluso plantean cierta dificultad para definirlo, es "muy difícil de determinar" (P2, MGD2) 1; "no pensé que me iba a pasar, pero el año pasado me diagnosticaron eso" (P1, HGD2). A la luz de sus planteamientos, los docentes perciben el estrés laboral en tres dimensiones: a niveles somático, emocional y de comportamiento. Así, identifican alteraciones en sus estados de ánimo, relaciones interpersonales, desempeño laboral, su liderazgo y en aspectos conductuales como el control de sí mismos: “... a lo mejor el mal genio, nos ponemos poco tolerantes, tenemos discusión entre nosotros...” (P3, MGD2).

En esa lógica, afirman que el estrés se manifiesta en alteraciones de sus funciones fisiológicas y psicológicas. Describen sufrir "problemas estomacales, el colon, como consecuencia de eso (...) el colesterol, la diabetes..." (P3, MGD1). Incluso reconocen una incidencia en el plano marital: "con mi esposo, inhibición del apetito sexual, para qué decirlo, no le cumplo como pareja" (P3, MGD1). En términos psicológicos, refieren "depresiones, insomnios, estados de angustia" (P1, MGD1). También reconocen que "toman medicamentos, se pichicatean $^{2}$ para poder seguir trabajando" (P5, HGD1).

En efecto, el concepto de estrés se asocia a sensaciones de que la situación laboral sobrepasa las posibilidades de automanejo del docente: "No querer más guerra (...) tirar todo para afuera" (P4, MGD2). Se trataría de un fenómeno percibido como amenazante que los vuelve "poco tolerantes", lo cual se manifiesta en "mal genio". En esa línea, lo definen también como una "condición para no poder rendir como tú quisieras" (P2, MGD2), como "algo ajeno a tu voluntad que te impide seguir avanzando, seguir estudiando, perfeccionándote, liderando" (P1, HGD2), situación que refleja una demanda incrementada en relación con sus recursos.

\footnotetext{
${ }^{1}$ Las citas se presentan codificadas de acuerdo a la descripción que se ejemplifica: (P2, MGD2), corresponde al Participante 2= P2; Mujer del Grupo de Discusión 2 (profesores urbanos) = MGD2; por tanto la sigla HGD1 por ejemplo, establece que se trata de un hombre perteneciente al Grupo de Discusión 1 , del ámbito rural.

${ }^{2}$ Auto administrarse medicamentos
} 
Cuando se les pregunta concretamente por su concepto de estrés, en general se capta cierta naturalización del fenómeno: "ya me acostumbré a ese ritmo, a este tipo de trabajo" (P3, MGD1), lo cual parece indicar una sensación de desesperanza aprendida.

\section{Estrés laboral y factores psicológicos personales}

En relación a las características personales y recursos para enfrentar la realidad que viven, se destaca la dificultad que perciben los profesores para adaptarse a realidades nuevas, problema que relacionan directamente con el estrés: "Nos cuesta adaptarnos al cambio y más encima estamos contra el tiempo y eso creo que nos afecta" (P7, MGD2). En este contexto, los profesores reconocen que hay momentos en los que se vivencian superados por el contexto: "... ya no puedo más" (P3, MGD2). Asimismo, aprecian que están perdiendo redes de apoyo, que nadie los contiene ni los escucha: “...necesitaríamos que (alguien) nos pudiera asistir, escuchar, contener" (P3, MGD2).

Relacionado a los estilos de afrontamiento, se aprecia cierto impacto en el plano psicológico individual, que se manifiesta en crecientes niveles de ansiedad, excesiva implicancia y auto exigencia laboral: "Nerviosa, preocupada, después en la cabeza me anda dando vueltas... soy como demasiado fanática, me preocupo mucho" (P3, MGD1). Esta conflictiva vivencia psicológica, tendría una repercusión directa en el contexto familiar de los docentes, quienes consideran que carecen de tiempo para sus familias, albergando sentimientos de culpa por ello, generando conflicto de roles, especialmente en las mujeres: “...los hijos ya están más grandes, se dan más cuenta (...) trato de hacer las dos cosas, pero como me considero responsable me dedico a mi trabajo" (P1, MGD1).

En síntesis, los profesores tienden a evaluar sus recursos psicológico-emocionales como escasos, reconociendo que sienten insatisfacción, frustración, bajo apoyo emocional y baja sensación de control de la situación. Tienden a no sentirse realizados personalmente, ni laboralmente y a verse a sí mismos con pocas herramientas para enfrentar las situaciones que los agobian. Así explican su relativa dificultad para adaptarse a situaciones nuevas, y la causa de la aparición de una variada sintomatología psicológica, donde destacan ansiedad, tensión, sobre implicancia laboral, conflicto de roles y desesperanza, todo lo cual repercute en el ámbito familiar.

\section{Estrés laboral y factores sociales}

Sobre los factores sociales, aparecen dos dimensiones percibidas como gravitantes a la hora de explicar la vivencia del fenómeno del estrés. Una corresponde a la dimensión social con una faceta cultural y política, y otra, es la dimensión cultural-generacional, referida a una visión del proceso histórico.

En efecto, los profesores se perciben inmersos en una realidad socio-culturalmente pobre, lo cual observan de manera particular en la escasa motivación por el estudio que presentan los estudiantes, quienes no valorarían la educación como instrumento de movilidad social: "No es una expectativa que les permita mejorar o cambiar su situación de vida en el futuro" (P1, MGD1). Este contexto, afectaría la labor docente, pues consideran que deben realizar esfuerzos desgastadores para que los estudiantes se motiven y aprendan.

A lo anterior, se agrega una marcada visión crítica de la cultura actual que, se centraría fundamentalmente en los derechos y no en los deberes: "Hoy en día se entiende que todos tenemos derechos, pero nadie pone un énfasis mayor en los deberes, en las obligaciones... y no están los derechos del profesor" (P5, HGD1). Se trata de una realidad contradictoria que impacta directamente en su quehacer, pues "la educación ha perdido, digamos, el rol valórico que tuvo durante muchas décadas" (P2, HGD1).

En términos del apoyo que proveen las familias a los alumnos, en especial los docentes de contextos urbanos, consideran que si bien las nuevas generaciones están acompañadas por padres con mejor nivel académico, no obstante éstos, no estarían acompañando el proceso académico de 
sus hijos: "Antes los profesores citaban a reunión y llegaban todos los apoderados" (P4, MGD2); "había más preocupación, más apoyo en los hogares" (P1, HGD2).

A juicio de los docentes, la juventud actual constituye una realidad social con serios problemas. En particular, los profesores de colegios urbanos perciben, que se trataría de jóvenes invadidos por la pornografía, las drogas, el alcoholismo, la prostitución y la delincuencia. Una generación que califican como irrespetuosa hacia los profesores, actitud que sería alimentada por los mismos padres. Ante esta realidad los docentes se sienten poco valorados: "Los tenemos aquí comportándose como delincuentes (...) niños que venden marihuana, niños que se han ido al baño a fumar marihuana, niñas que están en $6^{\circ}$ o $7^{\circ}$ que están embarazadas" (P3, MGD2).

También tienen una percepción negativa del contexto político-social, ligado particularmente al mundo educacional. En ese sentido, se consideran parte de un gremio muy castigado durante la historia: "Tenemos la famosa jubilación que nadie quiere tener (...) Se quieren ir porque están agotados, pero no se quieren ir porque después no van a tener plata para sobrevivir" (P6, HGD2). En esta línea, aparece mencionada la situación de violencia social, que es fuertemente percibida en los profesores rurales, para quienes este contexto los intranquiliza e inseguriza, sobre todo por el abuso de poder y la violencia institucional que se traduce en un hostigamiento permanente: "Carabineros está constantemente hostigando y esto con armas, controlando..." (P5, HGD1).

Respecto a la dimensión cultural-generacional, aparece una visión dicotómica de la historia. Perciben una realidad centrada en los derechos de los niños, pero donde no se respeta los derechos de los profesores y donde se han perdido los valores. Desde esta mirada, valoran positivamente y con añoranza un pasado que para ellos fue mejor. Critican los tiempos actuales, encarnados en las nuevas generaciones: "Es que no es como antes (...) a un niño uno le dice, te voy a poner un $1 \ldots$ póngame tres 1 , si quiere, ¿cuándo podíamos hacer eso nosotros antes?” (P1, HGD2), relatan con cierta desazón.

En esa línea, el discurso de los profesores está marcado por esta visión nostálgica del pasado: "Había mucho respeto, el profesor era realmente una autoridad" (P6, HGD2). Además, perciben que el poder adquisitivo de los docentes antes era mayor, mientras que, en términos de carga horaria, la modalidad previa a la Jornada Escolar Completa, les permitía desarrollar una vida más saludable: “...terminábamos a las dos de la tarde, y ya a las tres quedábamos libres (...) no estaba la presión que hay ahora" (P1, MGD1). En ese sentido, la convivencia de las comunidades educativas tampoco se daría como antes, donde supuestamente, primaban relaciones más cercanas, cohesionadas y cálidas: "Andábamos todo el día abrazadas, nos queríamos" (P4, MGD2).

En síntesis, los docentes conviven con una realidad socio-cultural que no les acomoda, donde ni estudiantes ni apoderados reconocen la importancia de la educación y donde además, los jóvenes están invadidos y permeados por la problemática social de estos tiempos. El contexto socio-político aparece como agobiador y especialmente violento en la ruralidad.

También se aprecia una mirada dicotómica de la historia; la añoranza de un pasado mejor, donde había respeto, convivencia, unidad, apoyo y familias funcionales y apoyadoras, características que en la actualidad no perciben, de ahí que se trata de un cambio cultural y generacional valorado negativamente por los docentes de ambos contextos.

\section{Estrés laboral y factores ambientales}


Es la categoría más mencionada en ambos contextos. Alude a los aspectos propios de la organización educativa; las relaciones interpersonales entre los miembros de la comunidad educativa, el liderazgo educacional, el rol docente, la carga de trabajo propia de la tarea de enseñar y aquella proveniente de exigencias administrativas o burocráticas.

En relación al liderazgo, en general manifiestan una mala experiencia con los líderes de las escuelas. Perciben que existe un exceso de jefaturas: “...tenemos jefes por todos lados y a cada uno se le ocurre lo que se le ocurre para justificar sueldo... y todo recae en nosotros" (P2, HGD2). Los docentes perciben que las autoridades tienden a amedrentar, más que ejercer una conducción positiva de la comunidad educativa; sienten miedo a reclamar y arbitrariedad en la adopción de medidas, factores que incidirían en un mal clima laboral: "toman represalias" (P5, HGD1).

Junto a esto, sienten temor y estrés por la evaluación docente a la que son sometidos periódicamente, pues a su juicio, en la práctica, éste sería un mecanismo que facultaría a las autoridades para desligarlos de sus fuentes laborales: “...coloca una categoría como en un nivel de profesores, como buenos, malos, más o menos, claro, entonces tú te puedes ir del sistema y va a ser difícil que te vayan a contratar..." (P2, HGD1).

Con respecto al papel que desempeñan, los profesores perciben una ambigüedad de rol que se transforma en demandante. Manifiestan que "el profesor tiene que hacerlo todo". En la escuela rural esta queja se da con particular insistencia, probablemente, como ellos mismos refieren, debido a que son establecimientos pequeños y con poco personal: "Desde lo más mínimo, no sé, preocuparse de tocar la campana o llevar el pan (...) Nos tenemos que preocupar de todo, absolutamente de todo" (P1, MGD1); “...el profesor es prácticamente la nana de los niños" (P5, HGD1); “...de verdad la hacemos toda ${ }^{3}$, hasta sacarles los piojos a los niños" (P3, MGD1).

Otro aspecto subrayado por los docentes es la sobrecarga de trabajo. Al respecto, mencionan la burocracia institucional, que califican de "terrible", pues perciben como excesiva la demanda administrativa, las planificaciones, el tener que responder a las emergencias de los contextos y actividades extraprogramáticas. En esta línea, aparece mencionada la Jornada Escolar Completa, explícitamente asociada con el estrés laboral docente: "nosotros pasamos a tener más de un rol: como guardería, cierto, desde poco antes de las 8 de la mañana, pasamos a tener otro rol acá en el colegio con los alumnos" (P2, MGD2).

La excesiva carga de trabajo, tendría como consecuencia el no cumplir con sus tareas docentes durante la jornada escolar, por lo que deben trabajar en sus casas. Esto, traería consecuencias importantes a nivel familiar: "Estoy deteriorando la relación que debo tener en mi casa... estás las 24 horas pensando, soñando, te despiertas en la noche, qué será de los niños" (P2, MGD2). En el ámbito rural, esta percepción es especialmente compartida: "El profe toda la vida se lleva parte de la escuela para la casa, pero ahora más" (P2, HGD1). También aluden a una muy reducida hora de almuerzo y la inexistencia de minutos de descanso entre una clase y otra: "Uno puede estar almorzando en cinco minutos, porque tiene que salir a mirar que es lo que ocurre (con los alumnos)" (P3, MGD1).

Los docentes también perciben negativamente las relaciones interpersonales en el espacio laboral, destacándose la pérdida de autoridad dentro de la sala de clases, que se manifiesta en una dificultad relacional con los estudiantes, al tratar de ejercer su rol. Esta situación es calificada como "muy estresante", particularmente por los profesores de colegios urbanos, quienes además reclaman una falta de autonomía en su desempeño: "Yo puedo hacer mi trabajo como corresponde y no tengo por qué tener a tanta gente en la sala" (P6, HGD2), aludiendo a la "irrupción" de otros profesionales de apoyo en el aula, como psicopedagogos y psicólogos.

El rol protagónico del docente en el proceso educativo también es un problema, pues manifiestan que se les atribuye a ellos, la exclusiva responsabilidad de que el alumno no aprenda.

\footnotetext{
${ }^{3}$ Se refiere a la cantidad y diversidad de tareas y actividades que deben cumplir
} 
Al respecto, declaran que se les exige que se evalúen, se reinventen, hagan clases entretenidas: “...la culpa la tenemos nosotros: es que usted colega no se hace una evaluación, que usted colega no se ha reinventado, es que usted colega a lo mejor es fome $e^{4}$ para hacer las clases. ¿Y quién dijo que teníamos que ser divertidos?" (P6, HGD2). A esto agregan la existencia de salas sobrepobladas de alumnos y una distancia generacional demasiado grande entre ellos y los estudiantes.

En términos generales, los docentes perciben una desvalorización de su labor. Sienten que luchan por sacar adelante a los estudiantes, pero no encuentran reconocimiento. De la mano de una mayor valoración del rol docente, también surge un llamado a alcanzar una mayor autonomía, factor que toma fuerza en un contexto apreciado negativamente, debido a la falta de retroalimentación organizacional: “¿Quién nos escucha?... ¿Quién nos retroalimenta?... No hay ningún respeto. No nos tienen respeto" (P4, MGD2).

Este sentir también surge en relación a los apoderados, de quienes no perciben apoyo. Según los profesores, son ellos quienes están supliendo a los padres en la tarea de criar, establecer disciplina, orden, normas y valores, que no se practicarían en la familia. Aprecian que los padres se han desligado del compromiso educador y que además se saltan los conductos regulares para incluso demandarlos con cierta "liviandad": "Si hoy en día te pones a pelear con un apoderado, van a hablar con el alcalde y te acusan al tiro de violencia, aunque a uno lo traten como la mona" (P2, MGD2).

En síntesis, entre los factores ambientales que inciden en el estrés laboral docente, los profesores reconocen principalmente elementos propios de la organización; liderazgos deficientes, roles docentes desconfigurados y poco espacio para la autonomía. Además, experimentan una carga de trabajo agobiante, debido a tareas administrativas y burocráticas. Las políticas educativas, también habrían afectado negativamente la función y valoración docente, percibiendo un trato injusto desde la institucionalidad educativa; sintiéndose amenazados y coartados en su derecho de opinar, reclamar e incluso a enfermarse.

A lo anterior se suman factores propios dificultan la actividad pedagógica; aulas sobrepobladas, alumnos desmotivados, desvinculación de los padres en su rol de crianza y acompañamiento, todo lo cual se suma a la carencia de valores que los ha hecho perder autoridad al interior de la comunidad educativa y protagonismo en el proceso de enseñanza-aprendizaje.

\section{Discusión}

Si bien el estrés laboral, es un fenómeno generado a partir de una serie de factores que se entrelazan de modo particular en cada sujeto, las opiniones recogidas en este estudio muestran que el contexto organizacional escolar es el ámbito más determinante de la tensión laboral de los profesores.

Al respecto, los docentes de la localidad de Collipulli perciben una serie de dificultades ambientales que dificultan el desarrollo de su labor profesional. De este modo, los profesores van mostrando un relato conformado por diferentes aspectos de la vida propiamente laboral, que los hace aparecer centrados, referidos y filtrando la realidad exclusivamente desde su vivencia en la escuela, perdiendo la perspectiva de otros factores, igual de gravitantes, que podrían incidir en su cansancio y en su potencial capacidad para afrontar las dificultades de la vida.

Los docentes, en general se vislumbran dentro de un andamiaje administrativo burocrático que les coarta la autonomía, los desvaloriza y menoscaba en su rol, pues se perciben como simples instructores o "cuidadores de niños", sin la identidad ni el estatus social que tenía el profesor de antaño. En ese sentido, esta investigación recoge directamente el malestar docente al que refieren

\footnotetext{
${ }^{4}$ Que aburre, o no motiva a los estudiantes
} 
otros estudios, aludiendo al sentimiento generado por la pérdida autoridad y de significatividad del rol del profesor, como resultado de una serie de transformaciones socioculturales y políticas ocurridas en las últimas décadas (Corvalán, 2005).

Especial consideración amerita la apreciación negativa de los profesores sobre el rol de las familias, quienes no cumplirían su rol como agentes socializadores; padres y apoderados que no asumen sus responsabilidades en la crianza, no cooperan con la escuela e incluso llegan a adoptar un rol oposicionista frente al profesor, antecedentes que confirman los hallazgos de la UNESCO en estudio de 2005, respecto a que uno de los indicadores más relevantes en el estrés de educadores es precisamente el abandono del rol educador de los padres.

El malestar docente también refiere al peso de la opinión crítica instalada en la sociedad respecto de que los docentes son responsables, en buena parte, de las deficiencias generales del sistema educativo. Es más, este sentimiento se convierte en verdadera nostalgia y tiñe la vivencia cotidiana del profesor, nutriendo una visión dicotómica de la historia, según la cual el tiempo pasado fue positivo y el presente está críticamente desmejorado.

Dado el profundo malestar y la nostalgia que albergan, es posible observar que los profesores aprecian sus problemas con cierto ensimismamiento, suscribiendo relatos autorreferentes, mostrándose un tanto ajenos a la realidad que viven otros actores sociales, y reconociendo abiertamente la necesidad de apoyo y contención psicológica para su tarea cotidiana. En ese sentido, este estudio arroja evidencia sobre el modelo de estrés de "desajustesesfuerzo-recompensa" de Siegrest, al mostrar que los profesores efectivamente relatan un desequilibrio entre los múltiples frentes en los cuales se esfuerzan y las recompensas que obtienen a cambio, tanto económicas como laborales y sociales.

Del mismo modo, los relatos y discursos aquí recogidos avalan el modelo de "demandacontrol" de Karasek, en el sentido de que los docentes sienten estrés como producto de un desempeño laboral exigente en términos cuantitativos (horas de trabajo, carga administrativa) y cualitativos (clima laboral, pérdida de significatividad), combinado con limitadas oportunidades para afrontar al agente estresor ("algo ajeno a tu voluntad").

En referencia al contexto social, aunque se trata de un factor que aparece mencionado con menos fuerza, los profesores de Collipulli se perciben inmersos en un entorno social que les resulta laboralmente adverso. En esto se observa una diferencia entre la visión de los profesores que trabajan en el contexto urbano y la de quienes lo hacen en el contexto rural. Los primeros identifican en la escuela la presencia de problemas transversales y propios de la sociedad actual, mientras que en el contexto rural los educadores palpan prioritariamente la tensión política derivada del conflicto mapuche (estresor social), sobre la cual no ejercen control y frente a la que no reciben apoyo social. A lo que se suma la percepción de ambigüedad de rol, por tener que desempeñar múltiples tareas, que promueven la insatisfacción laboral y desesperanza, y socavan su autoestima profesional.

Tras lo explicado, llama la atención que en los docentes de ambos contextos no aparezca con suficiente fuerza la influencia de los rasgos y recursos personales en el fenómeno del estrés. Existe una constante crítica generacional, a su rol y pérdida de autoridad, pero no aluden directamente a la necesidad de desarrollar habilidades interpersonales, estimular sus recursos internos, estilos y modos de atribución, así como su empoderamiento respecto de su rol social, lo que no les permite apreciar, por ejemplo, que el trabajo interdisciplinario ha devenido en una tendencia global. Es decir, la causalidad del estrés se percibe bajo la lógica de un locus de control externo y con rasgos motivacionales marcadamente exógenos, sumado una franca resignificación de los motivos causales como creencias y pensamientos automáticos.

En ese sentido, este estudio ofrece un aporte a la disciplina psicológica en general y al ámbito educativo en particular, ya que brinda una mirada cualitativa sobre un fenómeno por lo 
general alumbrado bajo el prisma cuantitativo, que indica que los profesores -al menos los de este estudio- sienten que las suyas son herramientas para enseñar a jóvenes de otra época y que se prepararon para un mundo distinto al que les tocó.

\section{Referencias}

Asún, D., Molina, D. \& Real, C. (2002). Burnout en educación. Documento de trabajo en el Seminario de Salud Laboral Docente, Facultad de Ciencias Sociales, Universidad de Chile, Chile.

Bryce, C. (2001). Insights lnto the Concept of Stress. Washington, DC, EE.UU: Panamerican Health Organization

Cornejo, R. (2008). Salud laboral docente: entre el sufrimiento individual y los sentidos colectivos. Revista Docencia, 35, 35-54. Recuperado de www.revistadocencia.cl/pdf/20100730180726.pdf

Cornejo, R. (2009). Condiciones de trabajo y bienestar/malestar docente en profesores de enseñanza media de Chile. Educação \& Sociedade, 30(107), 409-426. Doi: http://dx.doi.org/10.1590/S0101-73302009000200006

Corvalán, M. (2005). La realidad escolar cotidiana y la salud mental de los profesores. Revista Enfoques Educacionales, 7(1), 69-79. Recuperado de http://www.facso.uchile.cl/publicaciones/enfoques/09/Corvalan_N7 2005.pdf

Darrigrande, J. \& Durán, K. (2012). El síndrome de bornout y sintomatología depresiva en profesores: relación entre tipo de docencia y género en establecimientos subvencionados en Chile. REICE. Revista Iberoamericana sobre Calidad, Eficacia y Cambio en Educación, 10(3), 72-87. Recuperado de www.redalyc.org/articulo.oa?id=55124665006

Denzin N. K. (1989). Strategies of Multiple Triangulation. The Research Act: A theoretical Introduction to Sociological Methods. New York: McGraw Hill.

Díaz, R. \& Osses, S. (2013). Situación de la educación rural en territorios de la Araucanía, Chile. Un análisis con énfasis en lo medio ambiental y sociocultural. Bio-grafía Escritos sobre la Biología y su Enseñanza, (Edición Extra-Ordinaria), 582-589. doi: https://doi.org/10.17227/20271034.vol.0num.0bio-grafia582.589

Instituto Nacional de Estadísticas, INE (2004). Chile: Estimaciones y Proyecciones de Población por Sexo y Edad. País Urbano-Rural 1990-2020. Recuperado de www.ine.cl/canales/chile estadistico/demografia y vitales/proyecciones/Informes/Micro soft\%20Word\%20-\%20InforP UR.pdf

Jiménez, A., Jara, M. \& Miranda, E. (2012). Burnout, apoyo social y satisfacción laboral en docentes. Psicología Escolar e Educacional, 16(1), 125-134. Doi: http://dx.doi.org/10.1590/S1413-85572012000100013

Karasek, R. \& Theorell, T. (1990). Healthy Work, Stress, Productivity and the Reconstruction of Working Life. Nueva York: Basic Books

Krause, Mariane (1995). La investigación cualitativa. Un campo de posibilidades y desafíos. Revista temas de educación, 7, 19-39.

Krippendorff, Klaus (1990). Metodología de análisis de contenido: teoría y práctica. Barcelona: Paidós.

Krueger, R.A. (1988). Focus Groups: A practical guide for applied research. UK: Sage

Municipalidad de Collipulli (2012). Plan de desarrollo educativo municipal Collipulli 2012. En: www.municipalidadcollipulli.cl/files/1_PADEM_2012\%2008_11_1_DEFINITIVO.pdf

Napione, M. (2008). ¿Cuándo se quema el profesorado en secundaria? Madrid: Ediciones Díaz de Santos.

OMS. (2004). La organización del trabajo y del estrés: estrategias sistémicas de la solución de problemas para empleados, personal directivo y representantes sindicales. Serie Protección de la Salud de los Trabajadores, 3. Recuperado de https://www.who.int/occupational_health/publications/pwh3sp.pdf

Parra, M. (2005). Estudio de caso en Chile. En Robalino, M. \& Körner, A. (Coord.), Condiciones de trabajo y salud docente: estudios de casos en Argentina, Chile, Ecuador, México, Perú y Uruguay (75-102). Santiago de Chile: OREALC / UNESCO Santiago 
Robalino, M. \& Körner, A. (Coord.) (2005). Condiciones de trabajo y salud docente: estudios de casos en Argentina, Chile, Ecuador, México, Perú y Uruguay. Santiago de Chile: OREALC / UNESCO Santiago

Sandín, B. (2003). El estrés: un análisis basado en el papel de los factores sociales. International Journal of Clinical and Health Psychology, 3(1), 141-157. Recuperado de www.redalyc.org/pdf/337/33730109.pdf

Stake, R. (1999). Investigación con estudio de casos ( $2^{\mathrm{a}} \mathrm{ed}$.). Madrid: Ediciones Morata.

Taylor, S., \& Bogdan, R. (1987). Introducción a los métodos cualitativos de investigación. Barcelona: Paidós.

Vargas, L. (1994). Sobre el concepto de percepción. Alteridades, 4(8), 47-53. Recuperado de https://alteridades.izt.uam.mx/index.php/Alte/article/viewFile/588/586

Vera, D., Osses, S. \& Schiefelbein, E. (2012). Las Creencias de los profesores rurales: una tarea pendiente para la investigación educativa. Estudios Pedagógicos, XXXVIII(1), 311-324. doi: http://dx.doi.org/10.4067/S0718-07052012000100018

Villarroel, M., \& Wooding, J. (2005). Costos en la calidad de vida del profesor y su influjo en el rendimiento de los alumnos. Revista Iberoamericana de Educación, 36(5), 1-14. https://doi.org/https://doi.org/10.35362/rie3652796

Williamson, G. (2004). Estudio sobre la educación para la población rural en Chile. En Proyecto FAO-UNESCO-DGCS/ITALIA-CIDE-REDUC, Educación para la población rural en Brasil, Chile, Colombia Honduras, México, Paraguay y Perú (92-158). Recuperado de http://www.fao.org/3/y5517s/y5517s00.pdf

NOTA: Este artículo recoge los principales conceptos del trabajo de tesis realizado por los autores, para la obtención del grado académico de Licenciado en Psicología en la Universidad de las Artes, Ciencias y Comunicación (UNIACC), Chile. Investigación llevada a cabo durante el año 2014 y que lleva por título "Percepción de estrés laboral en profesores de la comuna de Collipulli" 